\title{
Effect of Domestic Violence on Pregnancy Outcomes among Rural and Urban Women
}

\author{
${ }^{(1)}$ Eman A. El-Hosary, ${ }^{(2)}$ AmanyA. Abd-Elsalam , \\ ${ }^{(3)}$ Dr.Abeer M.Emaghawry Eldeeb \\ (1) Lecturer of Maternal and Newborn Health Nursing, Faculty of Nursing, Menoufiya University, Egypt. \\ ${ }^{(2)}$ Lecturer of Maternal and Newborn Health Nursing, Faculty of Nursing, Menoufiya University, Egypt. \\ ${ }^{(3)}$ Assistant Prof. of Community and Family Health Nursing , Beni- Suef University, Egypt
}

\begin{abstract}
:
Background: Domestic violence against women during pregnancy is linked to poor outcome of pregnancy and a widespread global health problem with many negative consequences. Screening is effective in detecting domestic violence, and increases the rate of referrals to community resources, resulting in improved quality of life and fewer violence-related injuries.

The aim of the study: To identify the effect of domestic violence on pregnancy outcomes among rural and urban women.

Design: A descriptive correlational design was utilized for the study.

Setting: this study was conducted at maternal and child health centers for antenatal care (MCH Center) at Shebin El-kom.

Sample: A purposive sample of 240 pregnant women were recruited in the study.

Tools: Four tools were developed and used; 1) A structured interviewing questionnaire, 2) Hurting, Insulting and Threatening with harm screening tool (HITS); 3) A domestic violence screening scale 4) Edinburgh postnatal depression scale.

Results: The proportion of rural women who had experienced physical violence was significantly higher than that of the urban women $(41.7 \%$ versus $24.2 \%$, respectively; $P<0.05)$. Sexual violence was significantly higher among urban women than rural women $(31.7 \%$ versus $11.6 \%$, respectively; $P<0.05)$. There were no statistically significant differences in pregnancy outcomes among rural and urban women related to domestic violence.

Conclusion: Women are exposed to different forms of domestic violence during pregnancy. These forms of violence have an impact on the pregnancy outcomes such as abortions, low-birth weight, pre-term delivery, and postpartum depression among others.

Recommendations: based on the results of the present study we need to design education program for both the men and women regarding the effect of domestic violence on pregnancy outcomes.
\end{abstract}

Keywords: Domestic violence, Family violence, Pregnancy outcomes, Rural and Urban Women

\section{Introduction}

Domestic violence against women is one of the most pervasive abuses of human rights in the world, that lie in the spheres of those who are interested in the study of women's health and her rights. Violence against women is the barrier of women's empowerment and hinder the equal participation in society. However, they often go unnoticed and undocumented and therefore unresolved. Violence during pregnancy may threaten not only a woman well-being but that of her unborn child. Among women who had ever been pregnant six percent were hit, slapped, kicked or subjected to some other form of physical violence ( Bailey, 2012).

Moreover domestic violence known as spousal abuse or intimate partner violence (IPV), which is defined as "behavior within an intimate relationship that causes physical, sexual, or psychological harm, including acts of physical aggression, sexual coercion, psychological abuse and controlling behaviors" ( Audi, 2012). In addition, the World Health Organization (WHO) showed that, the prevalence of physical or sexual, or both type of violence varied from fifteen percent to seventy one percent in different countries. Physical injury, psychological problems and complications of pregnancy are some of the health consequences that result from violence inflicted on pregnant women by their intimate male partners (WHO, 2011).

Urquia et al., 2011, was reported that un attention has been given to domestic violence during pregnancy as global public health problem due to its adverse health consequences. An understanding of the effect of a partner's violence against a pregnant woman could have important reproductive health implications with early identification. It could also help in shaping future intervention programs. Pregnancy provides an opportunity to screen for domestic violence since pregnant women make routine antenatal visits. 
On the other hand, violence against women perpetrated by husbands occur in every society, but its prevalence and tolerance vary from country to country. Studies demonstrate that violence during pregnancy is more common in developing countries than developed countries and the consequence of domestic violence during pregnancy ranges from financial hardships and decreased intimacy to high rates of maternal and neonatal morbidity and mortality (Devries et al., 2010). Violence during pregnancy had a higher rates of preterm labor and intrauterine growth retardation than women without a history of violence, also domestic violence during pregnancy is associated with adverse pregnancy outcomes such as low birth weight, spontaneous abortion, bleeding during pregnancy, and higher neonatal deaths (Berenson et al., 2010)

Intimate partner violence during pregnancy is a serious public health issue which threatens fetal and maternal health, so the effects of intimate partner violence on women's health are increasing attention from local and international policy makers, and from the healthcare community, this is due to an increased awareness of the prevalence of violence. Also the government has recognized the need to increase the awareness, understanding, and recognition of domestic violence to encourage victims to come forward (Shah, 2010).

Researches has shown that nurses feel inadequately prepared to deal with victims of domestic violence and that a gap in practice and knowledge experience requires support and education, so antenatal care is very important for early detection of intimate partner violence, and is providing a suitable setting for addressing issues of violence. Asking questions may assist women to disclose their experiences of violence to health professionals and enable access to additional support and care, including community, legal and police support services (Flach et al., 2011).

\section{Significant of the study:}

Violence against women, committed by an intimate partner, is an important public health and human rights issue. In recent years, attention has focused also on intimate partner violence during pregnancy due to its prevalence, adverse health consequences and intervention potential. So, an understanding of the effect of a partner's violence against a pregnant woman could have important reproductive health implications with early identification. Pregnancy provides an opportunity to screen for domestic violence since pregnant women make routine visits during this period. Therefore, it is critical to explore the impact of violence on pregnancy outcomes in pregnant women.

The aim of the study:

To identify the effect of domestic violence on pregnancy outcomes among rural and urban women.

Research Questions

- What are the effects of domestic violence on pregnancy out comes?

- Are there a differences between domestic violence among rural and urban women?

\subsection{Research Design}

\section{Subjects and methods}

A descriptive correlateional design was used in the study.

\subsection{Research Setting}

The study was conducted at Maternal and Child Health Center Kebly (MCH Center) at Shebin El-Kom Menoufyia Governorate.

\section{3 sample:}

The sample used in the present study was non probability sample (purposive sampling). The sample size of 120 participants calculated using Dobson's formula.

$$
\mathrm{Z} 2 *(\mathrm{p}) *(1-\mathrm{p})
$$

Sample Size $=\frac{\text { c } 2}{\text { Sate }}$

$\mathrm{Z}=\mathrm{Z}$ value (e.g. 1.96 for $95 \%$ confidence level)

$\mathrm{p}=$ percentage picking a choice, expressed as decimal

(0.05 used for sample size needed)

$\mathrm{c}=$ confidence interval, expressed as decimal (e.g., .04 = \pm 4 )

The total sample size (240 participants of pregnant women at 24-40 weeks of gestation), composed of 120 participants from rural and 120 from urban area. The participants from both area were screened for domestic violence during pregnancy which revealed a relationship with the occurrence of adverse pregnancy outcomes.

2.4 Inclusion criteria: Pregnant women who exposed to domestic violence during pregnancy and free from any medical disease.

2.5 Data collection tools:- It was included Four parts as the following 
Part (1): A structured interviewing questionnaire; was developed by the researchers to collect data after extensive literature review related to1-a demographic characteristics (name, age, educational level); 1-b past obstetrical history; 1-c present obstetrical history.

Part (2): Hurting, Insulting and Threatening with harm screening tool (HITS); is a screening tool for domestic violence and intimate partner violence. Developed by Kevin Sherin in $\mathbf{2 0 0 3}$. It consisted of four items: physically hurting, insulting or talking down, threatening with harm, and screaming to the women. Each item is scored from 1-5. Thus, score for this inventory range from 4-20. A score greater than 10 is considered positive. This scale showed internal consistency and concurrent validity with verbal and physical violence and also showed constructed validity in its ability to differentiate family practice domestic violence than other.

Part (3): A domestic violence screening scale; was developed by the researchers to collect data after extensive literature review related to types of violence, duration, and health outcomes of violence in pregnancy and postpartum.

Part (4): Ediburgh Postnatal Depression Scale (EPDS); used to diagnose the symptoms of depression that were assessed by using the EPDS, an instrument covering common symptoms of depression and is designed to screen for risk of depression during the postnatal period, but can also be used during pregnancy (EDS). It is the most commonly-used screening tool; it was developed in England at health centers in Livingston and Edinburgh (1989). It is a 10-item screening questionnaire that is completed in minutes by the researcher. The sensitivity of $100 \%$ and specificity of $90 \%$ has been reported in community sample at 12 weeks postpartum at a score of 10 or higher. Each response is scored 0, 1, 2, 3 based on the increased severity of the symptoms. Calculate the total score by adding together each of the 10 items. A score of 10 or greater indicating the depressive symptoms ( Rubertsson et al., 2011)

\subsection{Ethical Consideration:}

\section{Methods of data collection}

An official permission was granted from the director of the maternal and child health centers. The researchers introduced themselves to the women who met the inclusion criteria and informed them about the purpose of this study in order to obtain their acceptance to share in this study. The researchers ensured that, the study posed no risk or hazards on their health and their participation in the study is voluntary. Pregnant women whose were willing to participate in the study and met the inclusion criteria were approached by the researchers and asked for verbal consent to confirm their acceptance, and all events that occurred during data collection were considered confidential

\subsection{Operational Design:}

The operational design includes preparatory phase, content validity, reliability, pilot study and fieldwork.

\subsection{Preparatory Phase:}

It includes reviewing of literature, different studies and theoretical knowledge of various aspects of the problems using books, articles, internet, periodicals and magazines.

\subsection{Validity \& reliability of tool:-}

Tool were submitted to a panel of five experts in the field of Maternity Nursing, Obstetric Medicine and community health nursing to test the content validity. Modifications were carried out according to the panel judgment on a clarity of the sentences and appropriateness of the content. The reliability test was assessed by using Cronbach's alpha test and pilot study by using test-retest.

\subsection{Pilot Study}

It was conducted on $10 \%$ of the study sample, were selected randomly and excluded from the main study sample. Its aim was to evaluate the simplicity and clarity of the tools. It also helped in the estimation of the time needed to fill in the forms. According to the results of the pilot study, simple modifications were done as rephrasing questions or canceling some questions.

\subsection{Field work:}

The pregnant women (24th-40thweek of pregnancy ) were asked by the researcher to participate in the study during their first visit to antenatal center, or at the visits for follow-up and vaccination. After obtaining ethical approval, the pregnant women were investigated by using an interview questionnaire. The researcher assessed pregnant women who exposed to domestic violence by using this questionnaire, at first the researcher introduced herself to the women before starting the data collection, then the purpose of the study was explained, the address and telephone number of each participant was taken for communication. The tool was filled in about 15 minutes to 30 minutes and the each pregnant woman received individually verbal and written information 
about the study. The researcher were asked every woman to answer the questionnaire in a private place, and the woman was promised about complete confidentiality.

Administrative Design:

Written letter including the aims of the study were issued from the Dean of the Faculty of Nursing, to the director of gynecological and obstetric clinic at Maternal and Child Health Center Kebly (MCH Center) at Shebin El-Kom to seek their approval for carrying out the study.

\section{Statistical Design:}

Data was collected and entered into a database file. Statistical analysis was performed by using the SPSS20 computer software statistical package. Qualitative data were expressed as number and percent (No \& $\%)$ then analyzed by applying chi-square test. Statistical significance was considered at P-value $<0.05$ and highly Significance at P-value $<0.00$.

\section{Results}

Table (1) Frequency and percentage distribution of sociodemographic characteristics of studied groups $(\mathrm{N}=240)$.

\begin{tabular}{|c|c|c|c|c|}
\hline \multirow{2}{*}{$\begin{array}{l}\text { Socio-demographic } \\
\text { Characteristics } \\
\text { Age of the wife }\end{array}$} & \multicolumn{2}{|c|}{$\begin{array}{c}\text { Rural women } \\
(\mathrm{n}=120)\end{array}$} & \multicolumn{2}{|c|}{$\begin{array}{l}\text { Urban women } \\
\qquad(\mathbf{n}=\mathbf{1 2 0})\end{array}$} \\
\hline & No. & $\%$ & No. & $\%$ \\
\hline$<25$ & 50 & 41.7 & 47 & 39.2 \\
\hline $25-35$ & 40 & 33.3 & 35 & 29.2 \\
\hline$>35$ & 30 & 25 & 38 & 31.7 \\
\hline Wife level of educational & & & & \\
\hline Illiterate & 9 & 7.5 & 7 & 5.8 \\
\hline Primary & 18 & 15 & 15 & 12.5 \\
\hline Secondary & 55 & 45.8 & 59 & 49.2 \\
\hline University & 38 & 31.7 & 39 & 32.5 \\
\hline Husband level of education & & & & \\
\hline Illiterate & 5 & 4.2 & 0 & 0 \\
\hline Primary & 11 & 9.2 & 9 & 7.5 \\
\hline Secondary & 58 & 48.3 & 55 & 45.8 \\
\hline University & 46 & 38.3 & 56 & 46.7 \\
\hline Occupation & & & & \\
\hline Worker & 35 & 29.2 & 44 & 36.7 \\
\hline House wife & 85 & 70.8 & 76 & 63.3 \\
\hline $\begin{array}{l}\text { Economic status (from the } \\
\text { participant point of view) }\end{array}$ & & & & \\
\hline High & 5 & 4.2 & 7 & 5.8 \\
\hline Moderate & 25 & 20.8 & 29 & 24.2 \\
\hline Low & 90 & 75 & 84 & 70 \\
\hline Parity & & & & \\
\hline 0 & 30 & 25 & 28 & 23.3 \\
\hline 1 & 33 & 27.5 & 30 & 25 \\
\hline $2-4$ & 50 & 41.7 & 52 & 43.3 \\
\hline$>4$ & 7 & 5.8 & 10 & 8.3 \\
\hline
\end{tabular}

Table (1) : shows that (41.7\%) of rural women and (39.2\%) of urban women their age less than 25 years, while $(45.8 \%)$ of rural women and $(49.2 \%)$ of urban women have secondary education. Regarding economic status (75\%) of rural women and $(71 \%)$ of urban women have low income from her point of view.

Table (2) Comparison of types and periods of domestic violence among rural and urban women in the studied group ( $\mathrm{N}=240)$.

\begin{tabular}{|c|c|c|c|c|c|}
\hline Type of violence & \multicolumn{2}{|c|}{$\begin{array}{c}\text { Rural women } \\
(n=120)\end{array}$} & \multicolumn{2}{|c|}{$\begin{array}{c}\text { Urban women } \\
(n=120)\end{array}$} & $P$-value \\
\hline $\begin{array}{l}\text { Physical } \\
\text { Psychological } \\
\text { Sexual } \\
\text { More than one type }\end{array}$ & $\begin{array}{c}50 \\
48 \\
14 \\
8\end{array}$ & $\begin{array}{c}41.7 \\
40 \\
11.6 \\
6.7\end{array}$ & $\begin{array}{l}20 \\
51 \\
38 \\
11\end{array}$ & $\begin{array}{c}16.6 \\
42.5 \\
31.7 \\
9.2\end{array}$ & $\begin{array}{l}<0.05^{*} \\
>0.05 \\
<0.05^{*} \\
>0.05\end{array}$ \\
\hline $\begin{array}{l}\text { Duration of violence } \\
<1 \text { year } \\
2-3 \text { year } \\
>3 \text { year }\end{array}$ & $\begin{array}{l}51 \\
44 \\
25\end{array}$ & $\begin{array}{l}42.5 \\
36.7 \\
20.8\end{array}$ & $\begin{array}{l}47 \\
49 \\
24\end{array}$ & $\begin{array}{c}39.2 \\
40.8 \\
20\end{array}$ & $>0.001$ \\
\hline
\end{tabular}

* statistically significant $(P<0.05)$ 
Table (2): illustrates that, a statistically significant differences between rural and urban women in physical violence $(41.7 \%$ versus $16.6 \%$, respectively; $\mathrm{P}<0.05)$. Sexual violence also was significantly higher among urban women than rural women $(31.7 \%$ versus $11.6 \%$, respectively; $\mathrm{P}<0.05)$. In contrast, there were no statistically significant difference between rural and urban women who had experienced psychological violence( $40 \%$ versus $42.5 \%$, respectively; $\mathrm{P}>0.05)$.

Table (3) Comparison of the perception of domestic violence among rural and urban women in the studied

\begin{tabular}{|c|c|c|c|c|c|}
\hline Variable & \multicolumn{2}{|c|}{$\begin{array}{c}\text { Rural women } \\
(n=120)\end{array}$} & \multicolumn{2}{|c|}{$\begin{array}{c}\text { Urban women } \\
(n=120)\end{array}$} & \multirow[t]{2}{*}{$P$-value } \\
\hline & No. & $\%$ & No. & $\%$ & \\
\hline $\begin{array}{l}\text { Women perception } \\
\text { Always excusable } \\
\text { Sometimes excusable } \\
\text { Not excusable } \\
\text { Undecided }\end{array}$ & $\begin{array}{l}19 \\
53 \\
22 \\
26\end{array}$ & $\begin{array}{l}15.8 \\
44.2 \\
18.3 \\
21.7\end{array}$ & $\begin{array}{l}25 \\
33 \\
30 \\
32\end{array}$ & $\begin{array}{c}20.8 \\
27.5 \\
25 \\
26.7\end{array}$ & $<0.05^{*}$ \\
\hline $\begin{array}{l}\text { Justification } \\
\text { Going out without telling } \\
\text { partner } \\
\text { Neglects the children } \\
\text { Argues with the partner } \\
\text { Refuses to eat } \\
\text { Refuses to prepare the food } \\
\text { Refuses to have sex }\end{array}$ & $\begin{array}{l}30 \\
46 \\
10\end{array}$ & $\begin{array}{c}25 \\
38.3 \\
8.3 \\
\\
12.5 \\
9.2 \\
6.7 \\
\end{array}$ & $\begin{array}{c}11 \\
\\
14 \\
35 \\
\\
18 \\
9 \\
33 \\
\end{array}$ & $\begin{array}{l}9.2 \\
11.7 \\
29.2\end{array}$ & $\begin{array}{l}<0.05^{*} \\
<0.05^{*} \\
<0.05^{*}\end{array}$ \\
\hline $\begin{array}{l}\text { Reaction } \\
\text { Report to family } \\
\text { Report to a close friend } \\
\text { Keep it secret }\end{array}$ & $\begin{array}{l}71 \\
19 \\
30 \\
\end{array}$ & $\begin{array}{c}59.2 \\
15.8 \\
25\end{array}$ & $\begin{array}{l}35 \\
22 \\
63\end{array}$ & $\begin{array}{l}29.2 \\
18.3 \\
52.5 \\
\end{array}$ & $\begin{array}{l}<0.001 * * \\
<0.001 * *\end{array}$ \\
\hline
\end{tabular}

Table (3): shows that, the proportion of women who believed that of domestic violence was sometimes excusable were significantly higher in the rural community than in the urban community $(44.2 \%$ versus $27.5 \%$, respectively; $\mathrm{P}<0.05$ ). A significantly higher proportion of rural women believed that going out without telling their partners or neglecting care for their children could justify domestic violence, while a significantly higher proportion of urban women believed that argues with the partner and refusing sex could justify domestic violence. While a higher proportion of rural women would report domestic violence to their families compared to urban women $(59.2 \%$ versus $29.2 \%$, respectively; $\mathrm{P}<0.001)$, a higher proportion of urban women keep domestic violence as a secret more than rural women $(52.5 \%$ versus $25 \%$, respectively; $\mathrm{P}<0.001)$.

Table (4) Association of domestic violence during pregnancy with pregnancy outcomes (N=240).

\begin{tabular}{|c|c|c|c|c|c|c|}
\hline Variable & \multicolumn{2}{|c|}{$\begin{array}{c}\text { Rural women } \\
(n=120)\end{array}$} & \multicolumn{2}{|c|}{$\begin{array}{c}\text { Urban women } \\
(n=120)\end{array}$} & \multirow[t]{2}{*}{$\mathbf{X}^{2}$} & \multirow[t]{2}{*}{ P -value } \\
\hline & No. & $\%$ & No. & $\%$ & & \\
\hline Low birth weight & 25 & 20.8 & 22 & 18.3 & 3.15 & $>0.001$ \\
\hline Premature rupture of membrane & 28 & 23.3 & 21 & 17.5 & 7.11 & $>0.001$ \\
\hline Abortion & 44 & 36.7 & 50 & 41.7 & 5.12 & $>0.001$ \\
\hline Abruptio placenta & 13 & 10.8 & 15 & 12.5 & 2.18 & $>0.001$ \\
\hline Bleeding & 10 & 8.3 & 12 & 10 & 1.71 & $>0.001$ \\
\hline
\end{tabular}

Table (4) clarifies that, $(20.8 \%)$ of rural women and (18.3\%) of urban women have low birth weight, also $(23.3 \%),(17.5 \%)$ of rural and urban women have premature rupture of membrane while, $(36.7 \%)$ of rural women, $(17.5 \%)$ of urban women have abortion. The table presents that, no statistically significant differences in pregnancy out comes between the rural and urban women $(\mathrm{p}>0.001)$. 
Figure (1) Association of domestic violence during pregnancy with postpartum complications( $\mathrm{N}=240)$.

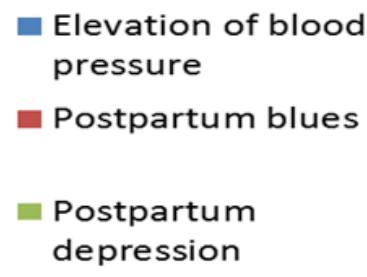

Figure (1): presents that, the highest proportion of postpartum complications occurs in postpartum blues and the lowest proportion occurs in postpartum depression among rural and urban women

$$
(36.6 \% \& 41.7 \% \text { respectively). }
$$

\section{Discussion}

Health care providers have a vital role in identifying the women at higher risk for domestic violence or intimate partner violence during pregnancy. However, it is well known that most health careers find it difficult to ask about it; they feel inadequately trained to do so, believe it is not their core business or that they do not have the skills to deal with that. Audi et al., (2012). The intention of this study was to identify the effect of domestic violence on pregnancy outcomes among rural and urban women because the violence poses many health risks to the pregnant women.

The current study revealed that the forty five percent of rural women and forty nine percent of urban women had a secondary level of education while seventy percent of rural women and sixty three percent of urban women were housewife, this result in agreement with Krug et al., (2012) who revealed that, the majority of pregnant women who exposed to violence were housewife lived in the rural area. From the researcher point of view, housewives experienced domestic violence more than workers women because they hadn't any authority and their husband is controlling of everything. They feel weakness and useless.

The current study findings showed that seventy five percent rural violent pregnant women and seventy percent of urban violent pregnant women had low economic status (from the women point of view). In the same line, Tejashri et al., (2013) reported that lower socioeconomic status was risk factors of domestic violence during pregnancy. Similarly, a study in the USA found that income and education were the most significant predictors of violence during pregnancy. The researcher opinion to this point, low socioeconomic status are significant risk factors for domestic violence especially in poverty areas because there are fewer resources, such as shelters and social service programs.

Regarding types of domestic violence the present study revealed that forty one percent of rural pregnant women more exposed to physical violence in compare with sixteen percent of urban pregnant women. This result, in agreement with these findings, Krug et al., (2012) who revealed that sixty nine percent of urban pregnant women more reported physical assaults by an intimate male partner. Furthermore, the overall prevalence of domestic violence during pregnancy in rural area is higher than in urban area.

Regarding sexual violence the present study concluded that thirty one percent of urban women experienced sexual violence compared with rural women which represents about eleven percent. This In contrast with Zacarias et al., (2012) who reported that the prevalence of psychological, physical, and sexual violence was thirty two percent, thirteen percent and six percent respectively. Seventeen percent of the victims suffered from three types of violence which was repeated and severe.

Concerning women perception to violence, the current study showed that, fifty two percent of the urban women compared with twenty two percent of the rural women respectively kept the violence from the intimate partner in secrete, this result in congruent with Kiely et al., (2010) who reported that the urban women did not like to talk about violence because the feeling of shame and guilt.

Moreover , Tejashri et al., (2013) added that, the women often don't report abuse because they find it hard to define themselves as victims or they blame themselves for the problem. Also there was a differences between rural and urban women in neglecting their children thirty eight percent and twelve percent respectively also arguing with the husband represents about eight percent, and twenty nine percent respectively, regarding refusing sexual relation with her husband forms six percent, twenty seven percent respectively, this was in 
congruent with Garcia-Moreno etal., (2013) who reported that abused women perception towards intimate partner violence takes various forms such as neglecting the children, arguing with the partner, and refusing the sexual relationship. The primary reason for that most abused women are not passive victims, but use active strategies to maximize their safety to herself and her children, while some women resist, others attempt to keep the peace by capitulating to their husband's demands.

It was also come out from the study that there is no differences between the rural and urban women regarding pregnancy outcome, while the highest proportion is abortion and the lowest is bleeding among both rural and urban women. In the same line Chai et al., (2016) documented that pregnancy outcomes for abused women being worse than those for non-abused women, for example abused pregnant women are at increased risk of abortion, preterm labor and having low birth weight infants. Women under domestic violence during pregnancy also have a higher risk of placental abruption, cesarean delivery, infection and hemorrhage, hypertension and vaginal bleeding, but the highest proportion is postpartum blues and the lowest in postpartum depression among rural and urban women. Also this result come in congruent with Nunes et al., (2011) who documented that domestic violence poses health risks to pregnant women including miscarriage, antepartum hemorrhage, premature birth, and depression in the postnatal period.

\section{Based on the result of the present study:}

\section{Conclusion}

The study was concluded that, women in the study sample are exposed to different forms of domestic violence during pregnancy. These forms of violence have an impact on the pregnancy outcomes such as abortions, low-birth weight, pre-term delivery, and postpartum depression among others. Also, there are a statistically significant differences between rural and urban women in physical and sexual violence and A significantly higher proportion of rural women believed that going out without telling their partners or neglecting care for their children could justify domestic violence, while a significantly higher proportion of urban women believed that argues with the partner and refusing sex could justify domestic violence. So the main duty of the health-care providers to actively screening for these mothers during pregnancy to help on reduction of maternal and fetal complications.

\section{Recommendations}

Based on the study results the researchers were recommended the following:

7.1 Organizing training program for nurses about early screening of intimate partner violence. Asking about intimate partner violence should be a part of routine antenatal care for early detection and identification of cases. 7.2 Supportive advocacy should be a prioritized intervention for community health services.

7.3 Designing and implementing an educational program to both the men and the women regarding the effect of domestic violence on pregnancy out comes.

\section{References}

[1]. Audi CA, Segall-Corrêa AM, Santiago SM, Pérez-Escamilla R. Adverse health events associated with domestic violence during pregnancy among Brazilian women. Midwifery. 2012;28:356-61

[2]. Bailey BA. Partner violence during pregnancy: Prevalence, effects, screening, and management. Int J Womens Health. 2010;2:18397. [PMC free article] [PubMed]

[3]. Berenson, A.B., Wierman, C.M., Wilkinson G.S., Jones, W.A. \& Anderson, G.D. (2010). Perinatal morbidity associated with violence experienced by pregnant women. Journal Article Research Support, Non-US Govt. Dol: 10.1016/5002-9378 (94) 703523.

[4]. Black M. C., Basile K. C., Breiding M. J., Smith S. G., Walters M. L., Merrick M. T., Stevens M. R. (2011). The National Intimate Partner and Sexual Violence Survey (NISVS): 2010 Summary Report. Atlanta, GA: National Center for Injury Prevention and Control, Centers for Disease Control and Prevention. Google Scholar.

[5]. Bhandari S., Bullock L., Bair-Merritt M., Rose L., Marcantonio K., Campbell J., Sharps P. (2012). Pregnant women experiencing IPV: Impact of supportive and non-supportive relationships with their mothers and other supportive adults on perinatal depression: A mixed methods analysis. Issues in Mental Health Nursing, 33, 827-837. Google Scholar Medline

[6]. Chai J, Fink G, Kaaya S, Danaei G, Fawzi W, Ezzati M, et al. Association between intimate partner violence and poor child growth: results from 42 demographic and health surveys. Bull World Health Organ. 016;94(5):331-9. Epub 2016/05/06. doi: 10.2471/blt.15.152462 pmid:27147763; PubMed Central PMCID: PMCPMC4850526.

[7]. Devries K. M., Kishor S., and Johnson H., "Intimate partner violence during pregnancy: analysis of prevalence data from 19 countries," Reproductive Health Matters, vol. 18, no. 36, pp. 158-170, 2010.

[8]. Flach C, Leese M, Heron J, Evans J, Feder G, Sharp D, et al. Antenatal domestic violence, maternal mental health and subsequent child behaviour: A cohort study. BJOG. 2011;118:1383-91. [PubMed]

[9]. Garcia-Moreno C, Pallitto C, Devries K, Stöckl Heidi, Charlotte , Charlotte Watts, et al. Global and regional estimates of violence against women: prevalence and health effects of intimate partner violence and non-partner sexual violence. World Health Organization. 2013.

[10]. Krug EG, Mercy JA, Dahlberg LL, Zwi AB. The world report on violence and health. Lancet 2012;360:1083-8

[11]. Kiely M., El-Mohandes AA., Gantz MG., Chowdhury D., Thornberry JS., El-Khorazaty MN. Understanding the association of biomedical, psychosocial and behavioral risks with adverse pregnancy outcomes among African Americans in Washington, DC. Matern Child Health J. 2011;15:S85-S95 [PMC free article] [PubMed]

[12]. Negussie D., Yemane B., Ellsberg M., Emmelin M., Kullgren G., and Hogberg U., "Violence against women in relation to literacy and area of residence in Ethiopia," Global Health Action, vol. 3, p. 2070, 2010. 
[13]. Nunes MA, Camey S, Ferri CP, Manzolli P, Manenti CN, Schmidt MI. Violence during pregnancy and newborn outcomes: a cohort study in a disadvantaged population in Brazil. Eur J Public Health. 2011;21(1):92-7. Epub 2010/02/26. doi: 10.1093/eurpub/ckp241 pmid:20181682.

[14]. Rubertsson C, Borjesson K, Berglund A, Josefsson A, Sydsjo G: The Swedish validation of Edinburgh Postnatal Depression Scale (EPDS) during pregnancy. Nord J Psychiatry. 2011, 65 (6): 414-418. 10.3109/08039488.2011.590606.

[15]. Shah PS. Knowledge synthesis group on determinants of preterm/LBW births. Maternal exposure to domestic violence and pregnancy and birth outcomes: A systematic review and meta-analyses. J Womens Health (Larchmt) 2010;19:2017-203

[16]. Tejashri D., Kazi K., Y. Chavan G., Velhal, and Aras R., "Study to assess determinants of domestic violence among women in UrbanSlumofMumbai," Journal of Dental and Medical Sciences, vol. 8, no. 4, pp. 18-22, 2013.

[17]. Urquia M. L, O'Campo P. J., I. Heaman M.,. Janssen P. A, and Thiessen K. R., "Experiences of violence before and during pregnancy and adverse pregnancy outcomes: an analysis of the Canadian Maternity Experiences Survey," BMC Pregnancy and Childbirth, vol. 11, article 42, 2011.

[18]. World Health Organization (WHO): Intimate Partner Violence during Pregnancy, World Health Organization (WHO), Geneva, Switzerland, 2011, http://www.who.int/repro

[19]. Zacarias A. E., Macassa G., Svanstr“om L., Soares J. J. F., and Antai D., "Intimate partner violence against women in Maputo city, Mozambique,” BMC International Health and Human Rights, vol. 12, no. 1, article 35, 2012. 